\title{
HOSPITAL UNIVERSITARIO DE SAN VICENTE FUNDACIÓN, UN CENTENARIO
}

\author{
Julio Ernesto Toro Restrepo MD*
}

Cumplir 100 años obliga a hacer un pare en el camino, mirar atrás y adelante para reflexionar acerca de lo recorrido y de lo que debe seguir. No se llega a un centenario porque si, por la simple pero maravillosa generosidad de la vida. Esto se logra con trabajo, con mucho trabajo, con amor, con entrega, con compromiso y con algo muy importante que puede pasar inadvertido a quienes no lo viven: la coherencia.

Ser coherentes es hacer lo que se piensa y lo que siente en el alma, y el Hospital ha sido coherente. Hoy 100 años después seguimos orientados por la misión trazada por su fundador. Cuando Don Alejandro Echavarría Isaza y un grupo de filántropos antioqueños decidieron fundar el hospital, lo visionaron como un hospital grande donde "tuviera cabida todo hijo de Antioquia y del resto del país que necesitara de sus servicios". Y así es. Somos un hospital grande en infraestructura, portafolio de servicios, número de empleados, número de atenciones, equipos de tecnología de punta y todo lo demás. Pero lo más importante es la grandeza de espíritu y corazón para ayudar a todos los que necesitan de nosotros.

Hoy en un sistema de salud a la merced de nuevos cambios y con inconformidad por parte de todos sus actores, enorgullece pensar que de la mano de Dios tenemos un hospital abierto a la población pobre y desprotegida que necesita de nosotros, y cuidamos de ellos con el esmero y dedicación que lo merecen, con los estándares de calidad exigidos por la acreditación para instituciones de alto nivel de complejidad. El ejercicio médico en el hospital obliga a enfrentarse al binomio más difícil del ser humano: la compleja enfermedad y la profunda desprotección. Y bajo estas condiciones debemos continuar ofreciendo a nuestros pacientes una esperanza de vida.

* Director General del Hospital SanVicente Fundación. Medellín, Colombia.
Enorgullece también reflexionar acerca de la relación con la academia, trazada desde los inicios del hospital, porque ilustres catedráticos de medicina de la época plasmaron su firma en el acta de fundación de la institución, como constancia de la relación indisoluble entre el hospital y la academia. En este recorrido institucional hemos conservado una relación sólida y fraterna con la Universidad de Antioquia, de gran beneficio para la sociedad médica de Colombia y el mundo, por los avances que en conjunto se han logrado en temas tan complejos como trasplantes. Diez universidades más de gran prestigio nos acompañan desde 2009, en un proceso por ampliarnos a la academia y permitir que el intercambio de conocimiento enriquezca el quehacer del hospital en beneficio de los pacientes.

La vocación docente persiste intacta y se fortalece en el tiempo con personal altamente calificado dispuesto a transmitir sus conocimientos para la formación de nuevas generaciones de médicos. Son cinco décadas formando especialistas y consolidando escuelas médicas de gran rigor académico.

Finalmente pensar en una institución de salud de alta complejidad dedicada a población vulnerable que cumple 100 años, nos lleva al imaginario del desgaste, las dificultades y probablemente la obsolescencia. Contrario a eso el hospital llega a este honroso cumpleaños en plena juventud, con importantes proyectos asistenciales y administrativos, a la vanguardia de la salud de alta complejidad en el país, buscando nuevas alternativas desde la investigación, la innovación y el desarrollo, y con capacidad renovada para los próximos 100 años.

¿Que Dios y la suerte nos acompañen para seguir adelante! 